\title{
Commentary: The over/under is set at 17? Let's not gamble with discharge after the Norwood operation
}

\author{
James M. Meza, MD, MSc, ${ }^{a, b}$ \\ Nicholas D. Andersen, MD, ${ }^{\mathrm{a}, \mathrm{b}, \mathrm{c}}$ and \\ Joseph W. Turek, MD, PhD ${ }^{\mathrm{a}, \mathrm{b}, \mathrm{c}}$
}

From discharge after the Norwood operation until stage 2 palliation, infants with hypoplastic left heart syndrome and its related malformations are at high risk for readmission, morbidity, and mortality as a result of parallel circulation and shunt-dependent pulmonary blood flow. From 2008 to 2016, the National Pediatric Cardiology Quality Improvement Collaborative (NPC-QIC) performed a multicenter, prospective study to guide quality improvement initiatives to improve outcomes during the interstage period. Through multivariable analysis of these data, Ahmed and colleagues ${ }^{1}$ developed the first validated risk score to guide decision making at discharge after the Norwood procedure, the NEONATE score, which they present in this issue of the Journal. The NEONATE score includes type of Norwood operation, use of extracorporeal membrane oxygenation after the Norwood operation, need for opiates at discharge, no digoxin versus digoxin prescribed at discharge, residual aortic arch obstruction, at least moderate tricuspid regurgitation, and need for extra oxygen.

A score of 17 or greater was associated with significantly lower transplant-free survival. With $55 \%$ sensitivity and $78 \%$ specificity, this cut point optimally identifies infants who are not at high risk. If an infant under consideration for discharge does not appear to be at low risk (eg, a

\footnotetext{
From the ${ }^{a}$ Duke Congenital Heart Surgery Research and Training Laboratory, Durham, NC; ${ }^{b}$ Division of Thoracic and Cardiovascular Surgery, Department of Surgery, Duke University Medical Center, Durham, NC; and 'Duke Children's Pediatric \& Congenital Heart Center, Durham, NC.

Disclosures: Authors have nothing to disclose with regard to commercial support.

Received for publication Nov 23, 2019; accepted for publication Nov 25, 2019; available ahead of print Dec 9, 2019.

Address for reprints: James M. Meza, MD, MSc, 2301 Erwin Rd, Box 3443, Durham, NC 27705 (E-mail: james.meza@duke.edu).

J Thorac Cardiovasc Surg 2020;160:1033-4

$0022-5223 / \$ 36.00$

Copyright (c) 2019 by The American Association for Thoracic Surgery

https://doi.org/10.1016/j.jtcvs.2019.11.094
}

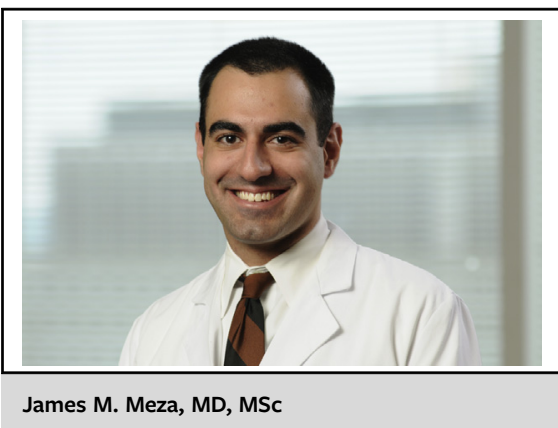

CENTRAL MESSAGE

The NEONATE score is a first step toward data-driven postNorwood decision making. Infants with a score of 17 or greater should remain hospitalized, and modifiable risk factors should be optimized.

NEONATE score $\geq 17$ ), the multidisciplinary team should strongly consider keeping the infant hospitalized. The score's modifiable risk factors could then guide further optimization of the infant's clinical condition, particularly regarding use of digoxin, need for opiates at discharge, supplemental oxygen, and tricuspid regurgitation. Digoxin is associated with improved outcomes after the Norwood operation. Failure to prescribe it has been strongly associated with death and transplantation. ${ }^{2,3}$ Furthermore, it is reasonable to delay discharge until opiate weaning has been completed, to remove an additional agent that may upset the precarious physiologic state of the Norwood circulation. Both should be part of a standardized post-Norwood discharge checklist.

Tricuspid regurgitation, along with home supplemental oxygen, should prompt strong skepticism toward an infant's suitability for discharge. Although the need for interval reintervention after the Norwood operation is already a known indicator of higher risk status, surgeons should not hesitate to address residual lesions or ongoing pathology that preclude an infant's discharge. ${ }^{4-6}$ At our institution, we advocate a policy of early, aggressive intervention on residual lesions or newly developed pathology, whether this means not terminating the index operation until the optimal result has been achieved or promptly 
reintervening when the clinical condition has failed to improve or has even worsened.

Building on the foundational studies of the post-Norwood course during the last 15 years from the Single Ventricle Reconstruction Trial, the Congenital Heart Surgeons' Society, and many individual institutions, the NEONATE score from Ahmed and colleagues ${ }^{1}$ an excellent and sorely needed first tool to aid decision making regarding discharge after the Norwood operation. Although the effect of this first step is certainly significant, the NEONATE score's primary limitation is that it can only be applied at the time of prospective discharge and does not use the NPC-QIC's extensive collection of longitudinal weight and oxygen saturation data throughout the interstage period. Future work should focus on the development of an updatable tool that quantifies risk and accounts for serial weight and oxygen saturation values, not only to maximize survival but to also produce the best possible candidates for stage 2 palliation.

\section{References}

1. Ahmed H, Anderson JB, Bates KE, Fleishman CE, Natarajan S, Ghanayem NS, et al. Development of a validated risk score for interstage death or transplant after stage I palliation for single ventricle heart disease. J Thorac Cardiovasc Surg. 2020;160:1021-30.

2. Oster ME, Kelleman M, McCracken C, Ohye RG, Mahle WT. Association of digoxin with interstage mortality: results from the Pediatric Heart Network Single Ventricle Reconstruction Trial public use dataset. J Am Heart Assoc. 2016;5: e002566.

3. Brown DW, Mangeot C, Anderson JB, Peterson LE, King EC, Lihn SL, et al; National Pediatric Cardiology Quality Improvement Collaborative. Digoxin use is associated with reduced interstage mortality in patients with no history of arrhythmia after stage I palliation for single ventricle heart disease. J Am Heart Assoc. 2016;5:e02376.

4. Nakata T, Fujimoto Y, Hirose K, Tosaka Y, Ide Y, Tachi M, et al. Atrioventricular valve repair in patients with functional single ventricle. J Thorac Cardiovasc Surg. 2010;140:514-21.

5. Hill KD, Rhodes JF, Aiyagari R, Baker GH, Bergersen L, Chai PJ, et al. Intervention for recoarctation in the Single Ventricle Reconstruction Trial: incidence, risk, and outcomes. Circulation. 2013;128:954-61.

6. Meza JM, Hickey E, McCrindle B, Blackstone E, Anderson B, Overman D, et al; Congenital Heart Surgeons' Society Timing of S2P Working Group. The optimal timing of stage-2-palliation after the Norwood operation. Ann Thorac Surg. 2018; 105:193-9. 